\title{
Erratum to: Assessment of physical activity in patients with chronic kidney disease and renal replacement therapy
}

William S. G. Hayhurst ${ }^{1,2^{*}}$ and Aimun Ahmed ${ }^{1,3}$

\section{Erratum to: SpringerPlus (2015) 4:536 \\ DOI 10.1186/s40064-015-1338-3}

The original version of the article (Hayhurst and Ahmed 2015) did not include the second affiliation of Dr. Aimun Ahmed. This has now been included in this erratum.

\section{Author details}

${ }^{1}$ Renal Department, Royal Preston Hospital, Lancashire Teaching Hospitals NHS Foundation Trust, Preston, UK. ${ }^{2}$ Medical School, University of Manchester, Manchester, UK. ${ }^{3}$ Nephrology Department, Faculty of Medicine, Ain Shams University, Cairo, Egypt.

The online version of the original article can be found under doi:10.1186/s40064-015-1338-3.

Received: 7 June 2016 Accepted: 7 June 2016

Published online: 04 July 2016

\footnotetext{
Reference

Hayhurst WSG, Ahmed A (2015) Assessment of physical activity in patients with chronic kidney disease and renal replacement therapy. SpringerPlus 4:536
}

\footnotetext{
*Correspondence: william.hayhurst@student.manchester.ac.uk

${ }^{1}$ Renal Department, Royal Preston Hospital, Lancashire Teaching

Hospitals NHS Foundation Trust, Preston, UK

Full list of author information is available at the end of the article
} provided you give appropriate credit to the original author(s) and the source, provide a link to the Creative Commons license, and indicate if changes were made. 